\title{
The Stochastic Optimization Scheduling Model for Wind Power, Thermal Power and Hydropower with Carbon Emissions Trading
}

\author{
Wu Hong-Liang ${ }^{1, *}$, Xin $\mathrm{He}^{2}$, Zhou Bao-Rong ${ }^{1}$, Dong $\mathrm{Nan}^{1}$ and Pan $\mathrm{Ge}^{2}$ \\ ${ }^{I}$ Electric Power Research Institute, CSG, Guangzhou 510080, China; ${ }^{2}$ North China Electric Power University, Beijing, \\ China
}

\begin{abstract}
Optimize generation resource joint scheduling is of great significance for the economic operation of power system and achieving emission reduction targets. To compare the economic and environment benefits between generation resource scheduling models, which are under different scheduling objectives and constraints, considering unit contribute, generation resources, and pollution constraints, this paper established three generation scheduling optimization models that under contract power mode, ideal energy - saving generation mode and the cooperation mode of the former two. On this basis, this paper put forward the power generation resource scheduling effectiveness evaluation model, and made a simulation, using the data of wind power, hydropower, and thermal power units. The results showed generation resources under the cooperation model joint scheduling optimization model can significantly reduce the discharge of pollutants, produce the least abandoned wind and abandoned water, the overall power generation profits are of $5.5 \%$ and $1.5 \%$, respectively, higher than the other two models, in summary, is able to obtain more comprehensive benefits.
\end{abstract}

Keywords: Emission constraints, energy saving and emission reduction, generation resources, joint scheduling, optimization model.

\section{INTRODUCTION}

Recently, Sustained and rapid development of China's economy led to a sharp increase in energy consumption and pollutant emissions, which makes our country face a huge crisis in energy sustainable supply and pressure of energy saving and emission reduction [1]. The Twelfth Five-year Plan requests unit of GDP and carbon dioxide emissions in 2015 to decrease $17 \%$ and $16 \%$ respectively compared to 2010. Generation resources joint optimization scheduling is able to promote the rational use of power resources, reduce electricity costs and pollutant emissions, meanwhile, it also advances energy saving and emission reduction for our society. Research on generation resources optimization scheduling still has some changes with the conversion of scheduling model $[2,3]$. In the period of planning dispatching, contract electricity is the main performance characteristics, the literature $[4,5]$ put forward preparation and decomposition algorithm of annual contract volume for thermal power electricity under the three modes which includes the traditional scheduling, full market, Limit pricing. In terms of energyefficient scheduling, the literature $[6,7]$ studied distribution network (DG) distributed power optimized configuration problems based on the multi-load level and multi-target load distribution question, which should reach to the target has smallest net loss and generating unit coal consumption. The literature [8-10] studied the economic compensation problem in energy-saving generation scheduling. Above documents made in-depth discussions for the establishment of generation resource scheduling model and its costs and benefits under certain scenarios. However, those documents lacked of comparison and analysis of all types of power generation resource scheduling under different targets and scenarios.

Considering the unit output, terms of generation resources, pollution and other constraints, this paper based on the above background regards the smallest generation costs and pollutant emissions cost as our target to construct the contractual power, the ideal energy generation scheduling and generating resource scheduling optimization model under the mutual cooperation scenarios of above two dispatching ways. On this basis, it also builds a power resource scheduling effectiveness evaluation mode.

\section{MANY TYPES OF POWER GENERATION RE- SOURCE SCHEDULING OPTIMIZATION MODEL BASED ON CONTRACT ELECTRICITY.}

Currently, Most of the research of generation resources scheduling almost prepare for a target has minimum total amount of coal consumption, and rarely comes to the cost of pollutant emissions. For this reason, many types of power generation resource scheduling optimization model is constructed that sets a goal has minimum coal consumption and pollutant emissions costs.

\subsection{The Objective Function}

We suppose that a region has $I$ generating units, and the output of unit NO. $i$ is $\mathrm{g}_{c i t}$ at the moment $t$, the relationships between coal consumption $F_{c i t}$ and output $\mathrm{g}_{c i t}$ are as following:

2015 Bentham Open 
$F_{c i t}=a_{i}+b_{i} g_{c i t}+c_{i} g_{\text {cit }}^{2}$

where: $a_{i}, b_{i}, c_{i}$ are the parameters determined by power generators historical data regression simulation.

We suppose that a region has $J$ generating units, and the output of unit NO. $j$ is $\mathrm{g}_{h j t}$ at the moment $t$, the relationships between water consumption $F_{h j t}$ and output $g_{h j t}$ are as following:

$F_{h j t}=a_{j}+b_{j} g_{h j t}+c_{j} g_{h j t}^{2}$

where: $a_{j}, b_{j}, c_{j}$ are the parameters determined through simulation.

Model objective function, chases the minimum total power generation coal consumption goal, is expressed as follows:

$$
\min \sum_{m=1}^{M} \sum_{t=1}^{T} \sum_{i=1}^{I} \eta_{e}^{k} P_{e}^{k}\left[u_{c i t}\left(1-u_{c i, t-1}\right) S_{c i}+u_{c i t} F_{c i t}\right]
$$

where: $S_{c i}$ represents the start consumption of coal-fired unit NO. $i, \eta_{e}^{k}$ represents the pollutant NO. $k$ emission rate in a unit of coal, $P_{e m}$ represents the pollutant NO. $k$ emissions charges prices.

\subsection{Constraints}

(1) Unit output balance constraints

$$
\sum_{i=1}^{I} u_{c i t} g_{c i t}+\sum_{j=1}^{J} u_{h j t} g_{h j t}+\sum_{k=1}^{K} u_{w k t} g_{w k t}=L_{t}
$$

where: $g_{\text {cit }}$ represents the output of Coal-fired unit $i$ at the moment $t, g_{h j t}$ represents the output of hydroelectric generating unit $\mathrm{j}$ at the moment $t, g_{w k t}$ represents the output of the wind turbine $k$ at the moment $t$.

(2) Unit output constraints

$$
\begin{aligned}
& u_{c i t} g_{c i}^{\min } \leq g_{c i t} \leq u_{c i t} g_{c i}^{\max } \\
& 0 \leq g_{h j t} \leq u_{h j t} g_{h j}^{\max } \\
& 0 \leq g_{w k t} \leq u_{w k t} g_{w k}^{\max }
\end{aligned}
$$

(3) Coal-fired unit output climbing constraint

$\Delta g_{c i}^{-} \leq g_{c i t}-g_{c i, t-1} \leq \Delta g_{c i}^{+}$

(4) Coal-fired units shortest start time constraint

$\left(T_{c i, t-1}^{o n}-M T_{c i}^{o n}\right)\left(u_{c i, t-1}-u_{c i t}\right) \geq 0$

where: $M T_{c i}^{o n}$ represents the minimum continuous running time of coal-fired unit $i, T_{c i, t-1}^{o n}$ represents the time that coalfired unit $i$ has continuous run at the moment $t-1$.

(5) Coal-fired units shortest downtime constrained
$\left(T_{c i, t-1}^{o f f}-M T_{c i}^{o f f}\right)\left(u_{c i t}-u_{c i, t-1}\right) \geq 0$

where: $M T_{c i}^{o f f}$ represents the minimum continuous taking off time of coal-fired unit $i, T_{c i, t-1}^{o f f}$ represents the time that coalfired unit $\mathrm{i}$ has continuous taken off at the moment $t-1$.

(6) Start-stop variable constraints

$u_{\text {cit }}=0$ or 1

$u_{\text {hjt }}=0$ or 1

$u_{w k t}=0$ or 1

(7) Water balance constraints

$V_{h j t+1}=V_{h j t}+W_{h j t}^{i n}-W_{h j t}^{o u t}-W_{h j t}^{s}$

where: $V_{h j, t+1}$ represents the reservoir $j$ storage at the end of moment $t, V_{h j t}$ represents the reservoir $j$ storage at the moment early $t, W_{h j t}^{i n}$ represents the amount of storage water at the moment $t, W_{h j t}^{\text {out }}$ represents the amount of power water of reservoir $j$ at the moment $t, W_{h j t}^{s}$ represents the abandoned water of reservoir $j$ at the moment $t$.

(8) Reservoir storage capacity constraints

$V_{h j t}^{\min } \leq V_{h j t} \leq V_{h j t}^{\max }$

where: $G$ represents the minimum storage capacity of the reservoir $J$ that should be guaranteed at the moment $t$, H represents the maximum storage capacity of the reservoir $J$ that should be guaranteed at the moment $t$.

(9) Vent flow constraints

$W_{h j t, q}^{\min } \leq W_{h j t, q} \leq W_{h j t, q}^{\max }$

where: $W_{h j t, q}^{\min }$ represents the minimum discharge of the reservoir $J$ that should be guaranteed at the moment $t, W_{h j t, q}$ represents the maximum allowable discharge $f$ the reservoir $J$ that should be guaranteed at the moment $t, W_{h j t, q}^{\max }$ represents the discharge of the reservoir $J$ at the moment $t$.

(10) Generating water consumption constraints of station

$F_{h j t} \leq V_{h j t}$

(11) Hydropower output constraints

$$
\begin{aligned}
& g_{h j t}=\alpha_{j} * W_{h j t, q} * H_{j t} \\
& g_{h j t}^{\min } \leq g_{h j t} \leq g_{h j t}^{\max }
\end{aligned}
$$

where: $H_{j t}$ represents the water head of the reservoir $J$ at the moment $t, \alpha_{j}$ represents the output coefficient of the reservoir $J, g_{h j t}^{\min }$ represents the minimum output allowed by power station, $g_{h j t}^{\max }$ represents the maximum output allowed by power station.

(12) Wind turbine technology constraints 


$$
g_{w k t}^{*}=\left\{\begin{array}{lc}
0 & v(t) \leq v_{I, j} \quad \mathrm{ov}(t)>v_{O, j} \\
\varphi_{j}(v(t)) & v_{I, j} \leq v(t) \leq v_{R, j} \\
g_{w k}^{\max } & v_{R, j} \leq v(t) \leq v_{O, j}
\end{array}\right.
$$

where: $v(t)$ represents the wind speed at the moment $t$, $v_{I, i}$ represents the cut-in speed of the wind turbine $j, v_{O, i}$ represents the cut-out speed of the wind turbine $j, v_{R, j}$ represents the available generating capacity of wind turbines $j$, $\phi_{j}(v(t))$ represents the rated wind speed of the wind turbine $j, g_{w k}^{\max }$ represents the wind power curve of the wind turbine $j, g_{w k t}^{*}$ represents the power upper limit of the wind turbine $j$.

$\varphi_{j}(v(t))=\frac{1}{8} \eta_{1} \eta_{2} \eta_{3} \rho \pi d^{2} v^{3}(t)$

where: $\eta_{1}$ represents the power coefficient of the wind turbine, its value usually between 0.2 to 0.5 , and the maximum is $0.593 ; \eta_{2}$ represents mechanical efficiency of wind turbine gear, $\eta_{3}$ represents the mechanical efficiency of the generator, $\rho$ represents air density; D represents wind turbine rotor diameter.

$0 \leq g_{w k t} \leq g_{w k t}^{*}$

(13) Pollutant emission constraints

$\eta_{e}^{k} \sum_{t=1}^{T} \sum_{i=1}^{I}\left[u_{c i t}\left(1-u_{c i, t-1}\right) S_{c i}+u_{c i t} F_{c i t}\right] \leq Q_{e k}^{\max }$

where: $Q_{e k}^{\max }$ represents the maximum emission constraints of pollutants NO. $\mathrm{k}$ during the period $\mathrm{T}$.

(14) Generating contract constraints

$\sum_{t=1}^{T} u_{c i t} g_{c i t} \geq Q_{c i}^{c}$

where: $\mathrm{H}$ represents the allocated contract power of coalfired unit $i$ during the period $\mathrm{T}$.

$\sum_{t=1}^{T} u_{h j t} g_{h j t} \geq Q_{h j}^{c}$

where: $\mathrm{H}$ represents the allocated contract power of hydropower unit $\mathrm{j}$ during the period $\mathrm{T}$.

$\sum_{t=1}^{T} u_{w k t} g_{w k t} \geq Q_{w k}^{c}$

where: $\mathrm{H}$ represents the allocated contract power of wind Turbine $\mathrm{k}$ during the period $\mathrm{T}$.

3. MANY TYPES OF POWER GENERATION RESOURCE SCHEDULING OPTIMIZATION MODEL BASED ON THE IDEAL ENERGY-SAVING GENERATION SCHEDULING MOEDL.

In the ideal energy-saving scheduling environment, Multi-resource scheduling optimization model sets a target that has the minimum total costs of coal-fired power generation and start-stop of thermal power, Specific objective function is as follows:

$\min \sum_{m=1}^{M} \mu_{e m} P_{e m} \sum_{t=1}^{T} \sum_{i=1}^{I}\left[\begin{array}{l}u_{c i t}\left(1-u_{c i, t-1}\right) S_{c i} \\ +u_{c i t} F_{c i t}\end{array}\right]$

Constraint formulas are (3-26)

Taking into account the randomness and volatility of wind turbine output and the large-scale wind power installed easily lead to a large number of abandoned wind phenomenon, this model gives wind power the maximum penetration constraint to ensure the stability of the power grid, the specific constraints are as follows:

$P_{t}^{w} \leq \beta L_{t}$

where: $\beta$ on behalf of wind power limit penetration, $\%$.

\section{MANY TYPES OF POWER GENERATION RE- SOURCE SCHEDULING OPTIMIZATION MODEL BASED ON THE COOPERATION MODEL}

This paper integrates those characteristics of many types of power generation resource scheduling optimization model of contract power and ideal energy-saving generation scheduling, what's more, it constructs the multi-class power resource scheduling optimization model of cooperation model, and the objective function is similar to the objective function in the ideal energy-saving generation scheduling.

Constraints:

(1) constraint formula are (3-26) an (28)

(2) Contract power constraints:

$\sum_{i=1}^{I} \sum_{t=1}^{T} u_{c i t} g_{c i t} \geq \sum_{i=1}^{I} Q_{c i}^{c}$

\section{EFFECTIVENESS EVALUATION MODEL OP GENERATION RESOURCE SCHDULING}

Effective evaluation model aims at the three scheduling model is established based on the previous text, decision variable values are $u_{c i t}^{(i)}, F_{c i t}^{(i)}, g_{c i t}^{(i)}, g_{h j t}^{(i)}, g_{w k t}^{(i)}(\mathrm{i}=1,2,3)$, The costs and benefits is calculated as follows:

\subsection{Coal Consumption}

$C_{c}^{(k)}=\sum_{t=1}^{T} \sum_{i=1}^{I}\left[u_{c i t}^{(k)}\left(1-u_{c i, t-1}^{(k)}\right) S_{c i}+u_{c i t}^{(k)} F_{c i t}^{(k)}\right]$

where: $\mathrm{k}$ represents the scheduling kind NO. $\mathrm{v}(\mathrm{k}=1,2,3)$, $C_{c}^{(k)}$ represents the coal consumption under the scheduling ways NO. k.

\subsection{Pollution Emissions}

$C_{e}^{(k)}=\sum_{k=1}^{K} \sum_{t=1}^{T} \sum_{i=1}^{I} \eta_{e}^{k}\left[\begin{array}{l}u_{c i t}^{(k)}\left(1-u_{c i, t-1}^{(k)}\right) S_{c i} \\ +u_{c i t}^{(k)} F_{c i t}^{(k)}\end{array}\right]$ 
Table 1. Coal-fired turbine power generation parameters.

\begin{tabular}{|c|c|c|c|c|c|c|c|c|c|c|}
\hline Units & $a_{j}$ & $b_{j}$ & $c_{j}$ & $\begin{array}{c}T_{j}^{o n} \\
\text { (h) }\end{array}$ & $\begin{array}{c}T_{j}^{o f f} \\
\text { (h) }\end{array}$ & $\begin{array}{c}S C_{\mathrm{j}} \\
\text { (t) }\end{array}$ & $\begin{array}{l}P_{j, t}^{\min } \\
\text { (MW) }\end{array}$ & $\begin{array}{l}P_{j, t}^{\max } \\
\text { (MW) }\end{array}$ & $\begin{array}{c}\ddot{A} P_{j}^{+} \\
\text {(MW/h) }\end{array}$ & $\begin{array}{c}\ddot{A} P_{j}^{-} \\
\text {(MW/h) }\end{array}$ \\
\hline $1 \#$ & 8.8 & 0.268 & $9.44 \mathrm{E}-06$ & 7 & 7 & 22.3 & 200 & 450 & 210 & -210 \\
\hline $2 \#$ & 4.6 & 0.304 & 4.13E-05 & 4 & 4 & 8.1 & 100 & 250 & 100 & -100 \\
\hline $3 \#$ & 1.4 & 0.314 & $8.35 \mathrm{E}-05$ & 2 & 2 & 2.1 & 30 & 100 & 50 & -50 \\
\hline
\end{tabular}

Table 2. Hydropower generating unit parameters.

\begin{tabular}{|c|c|c|c|c|c|c|}
\hline Units & $\begin{array}{c}W_{\max } / \\
\left(\mathbf{m}^{\mathbf{3} / \mathbf{s})}\right.\end{array}$ & $\begin{array}{c}W_{\min } / \\
\left(\mathbf{m}^{\mathbf{3} / \mathbf{s})}\right.\end{array}$ & $\begin{array}{c}V_{\max } / \\
\left(\mathbf{1 0}^{\mathbf{8}} \mathbf{m}^{\mathbf{3}}\right)\end{array}$ & $\begin{array}{c}V_{\min } / \\
\left(\mathbf{1 0}^{\mathbf{8}} \mathbf{m}^{\mathbf{3}}\right)\end{array}$ & $\begin{array}{c}\boldsymbol{\alpha} / \\
\mathbf{1 0}\end{array}$ & $\begin{array}{c}\mathbf{1 0}^{-4} \\
\mathbf{m}\end{array}$ \\
\hline \hline 1 & 57 & 23 & 500 & 55 & 29 & 50 \\
\hline
\end{tabular}

Table 3. Wind turbine power output and load demand data.

\begin{tabular}{|c|c|c|c|c|c|}
\hline Period & $\begin{array}{l}\text { Available Output of } \\
\text { Wind Power /MW }\end{array}$ & Load Demand & Period & $\begin{array}{l}\text { Available Output of } \\
\text { Wind Power /MW }\end{array}$ & Load Demand \\
\hline 1 & 95.33 & 333 & 13 & 56.33 & 833 \\
\hline 2 & 171.17 & 334 & 14 & 47.67 & 767 \\
\hline 3 & 177.67 & 367 & 15 & 71.50 & 700 \\
\hline 4 & 186.33 & 400 & 16 & 86.67 & 600 \\
\hline 5 & 173.33 & 500 & 17 & 80.17 & 567 \\
\hline 6 & 145.17 & 567 & 18 & 62.83 & 633 \\
\hline 7 & 127.83 & 633 & 19 & 45.50 & 700 \\
\hline 8 & 101.83 & 700 & 20 & 43.33 & 833 \\
\hline 9 & 60.67 & 767 & 21 & 71.50 & 767 \\
\hline 10 & 62.83 & 833 & 22 & 97.50 & 633 \\
\hline 11 & 56.33 & 867 & 23 & 141.27 & 433 \\
\hline 12 & 65.00 & 900 & 24 & 123.50 & 333 \\
\hline
\end{tabular}

where: $C_{e}^{(k)}$ represents the total amount of generation pollution emissions under the scheduling ways NO. $\mathrm{k}$.

\subsection{Units Generating Profits}

$R_{c}^{(k)}=\sum_{t=1}^{T} u_{c i t}^{(k)} g_{c i t}^{(k)}\left(P_{c i t}-C_{c i t}\right)$

where: $R_{c}^{(k)}$ represents the thermal power generating profits under the scheduling ways NO.

$\mathrm{k} ; P_{\text {cit }}$ represents the tariff of thermal power unit i under the scheduling ways NO. k at time t; $C_{c i t}$ represents the unit cost of electricity of thermal power unit $i$ under the scheduling ways NO. $\mathrm{k}$ at time $\mathrm{t}$.

$R_{h}^{(k)}=\sum_{t=1}^{T} u_{h j t}^{(k)} g_{h j t}^{(k)}\left(P_{h j t}-C_{h j t}\right)$ where: $R_{h}^{(k)}$ represents the hydroelectric units generating profits under the scheduling ways NO. k; $P_{h j t}$ represents the tariff of thermal power unit $\mathrm{j}$ under the scheduling ways NO. $\mathrm{k}$ at time $\mathrm{t} ; C_{h j t}$ represents the unit cost of electricity of thermal power unit $\mathrm{j}$ under the scheduling ways NO. $\mathrm{k}$ at time $\mathrm{t}$.

$R_{w}^{(k)}=\sum_{t=1}^{T} u_{w k t}^{(k)} g_{w k t}^{(k)}\left(P_{w k t}-C_{w k t}\right)$

where: $R_{w}^{(k)}$ represents the hydroelectric units generating profits under the scheduling ways NO. k; $P_{w k t}$ represents the tariff of thermal power unit $\mathrm{j}$ under the scheduling ways NO. $\mathrm{k}$ at time $\mathrm{t} ; C_{w k t}$ represents the unit cost of electricity of thermal power unit $\mathrm{j}$ under the scheduling ways NO. $\mathrm{k}$ at time $\mathrm{t}$. 
Table 4. The output of thermal power units in three scenes.

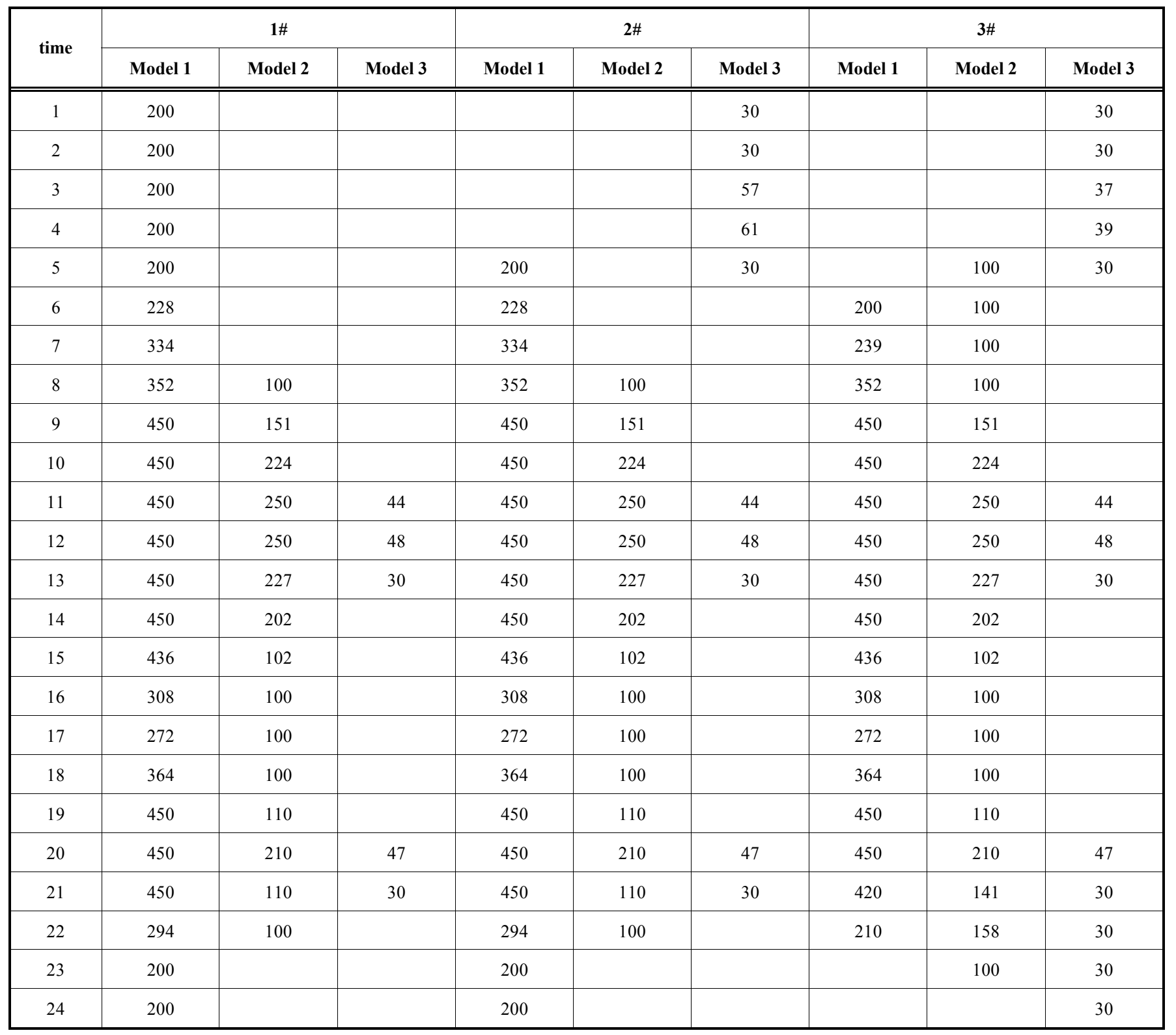

\section{NUMERICAL EXAMPLES}

\subsection{Initial Data}

This paper collect the available output of three thermal power units, one hydropower unit and wind turbines of a region as an example initial data. Thermal power units and hydropower units generating set parameters show in Table $\mathbf{1}$ and 2. The power load demand of this region on one day and the available output of wind turbines are shown in Table 3. We assume the evaluation of the cost of power generation is 0.1 yuan $/ \mathrm{kW} \cdot \mathrm{h}$ in this region, meanwhile, the tariff of wind power, thermal power and hydropower are $0.61,0.45$, 0.32 yuan $/ \mathrm{kW} \cdot \mathrm{h}$ respect in this region. In the energyefficient scheduling environment, the total amount of wind power is still increasing. In this paper, wind power limit penetration of resource scheduling model under an ideal energy-generating scheduling is assumed to be $50 \%$ due to the large amount of wind energy resources in the region.

\subsection{Numerical Example Results}

\subsubsection{Units Output Comparison}

In the contract electricity model, the contract electricity is assigned to the three thermal power units are 7539, 1836, $143 \mathrm{MW} \cdot \mathrm{h}$ respectively. Furthermore, the contract electricity amount of wind power and hydropower is still 2000MW • h. however, the contract generating electricity doesn't need to be assigned in an ideal energy-saving generation scheduling model, Unit output scheduling is sorted in full accordance with the unit coal consumption. The total contract electricity, in cooperation model, is assigned to the thermal power units reach to $9300 \mathrm{MW} \cdot \mathrm{h}$, but it doesn't assign to specific units, the power scheduling of thermal power and other generator sets is according to energy-saving scheduling model. Output condition of above three thermal power units are shown in Table 4, wind power and hydropower output situation shown in Figs. (1-3) respectively. 


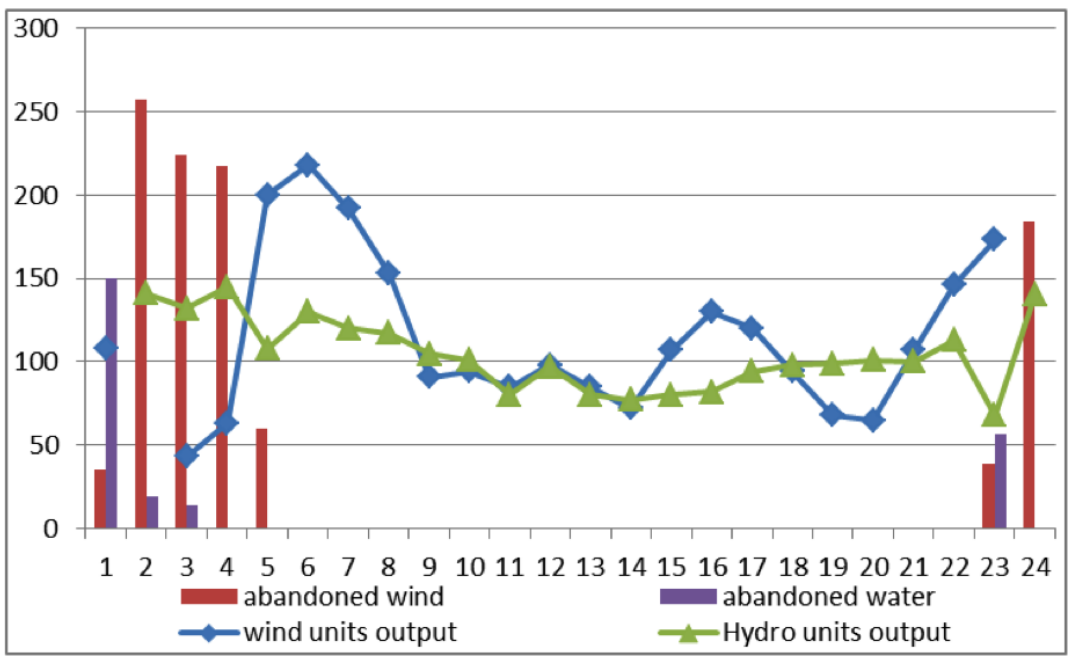

Fig. (1). The output of wind power and hydropower units of model 1 (unit: MW).

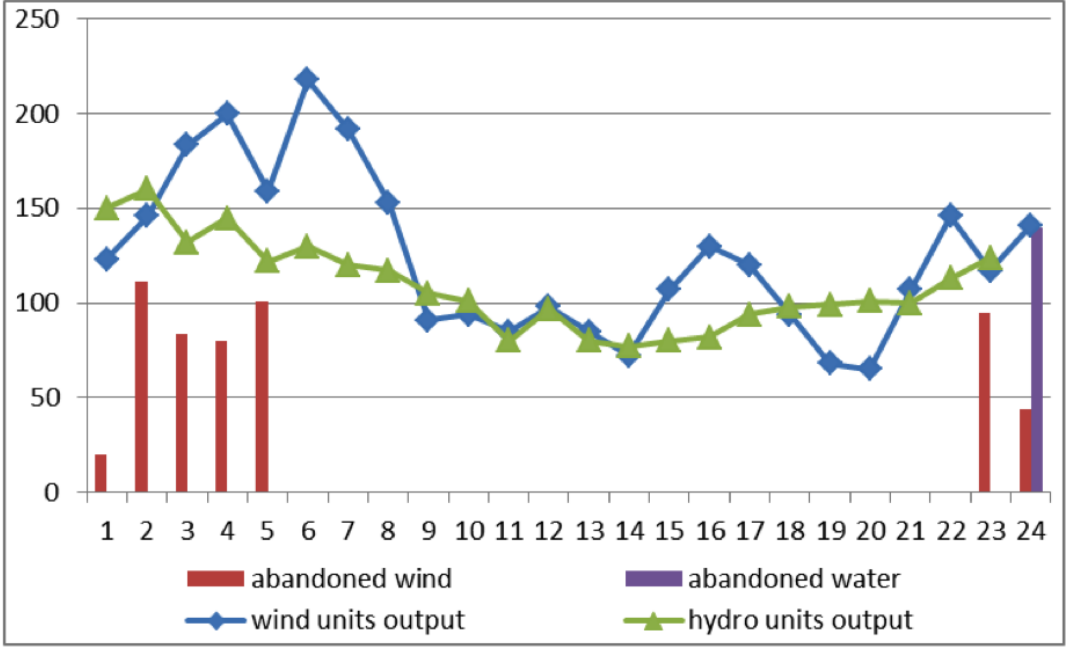

Fig. (2). The output of wind power and hydropower units of model 2(unit: MW).

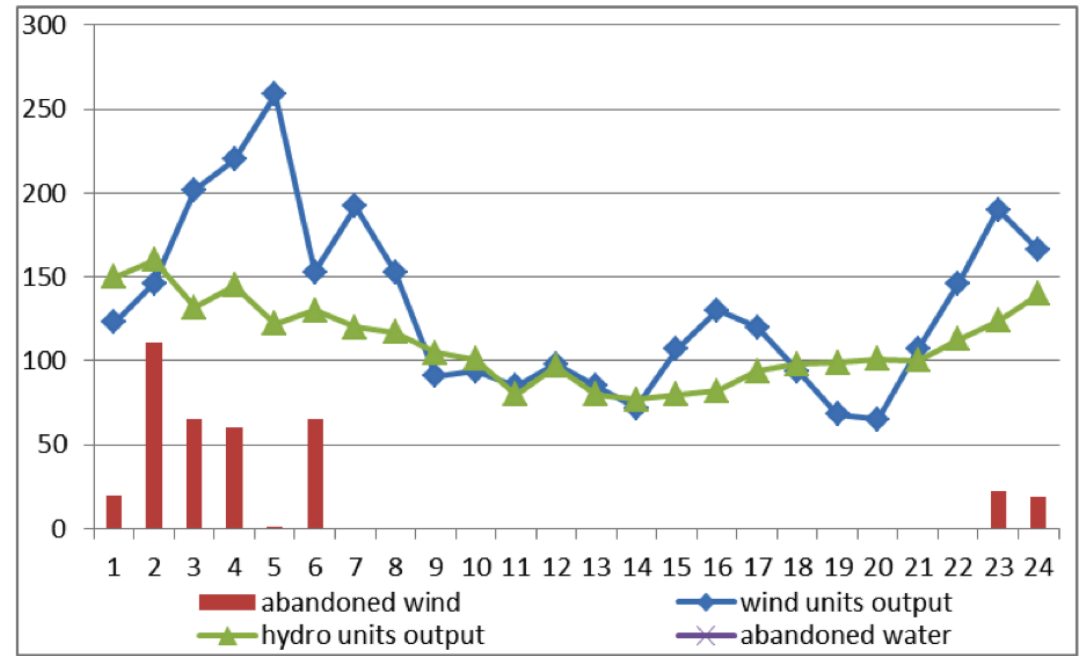

Fig. (3). The output of wind power and hydropower units of model 3 (unit: MW).

Analysis results are shown below according to Table 4:

Thermal power output is higher than the contract power in the contract power model, which is obtained by comparing above three models. Among them unit $1 \#$ has been invoked in the scheduling period due to lower coal consumption, however, unit $2 \#$ and unit $3 \#$ are invoked during the peak of load demand, output comes from wind power and hydropower units in the rest of time, in an ideal energy-saving generation scheduling model, at 1-4 hours, the wind turbine 
Table 5. Pollutant emissions comparison of the three models.

\begin{tabular}{|c|c|c|c|c|c|c|c|}
\hline & \multicolumn{2}{|c|}{ Coal-fired power generation cost / tce } & \multicolumn{3}{c|}{ Emissions / tonne } \\
\cline { 2 - 8 } & $\begin{array}{c}\text { Coal-Fired Power } \\
\text { Generation Costs }\end{array}$ & $\begin{array}{c}\text { Start-Stop } \\
\text { Cost }\end{array}$ & Total Cost & $\begin{array}{c}\text { SO }_{2} \\
\text { Emissions }\end{array}$ & $\begin{array}{c}\text { CO }_{2} \\
\text { Emissions }\end{array}$ & $\begin{array}{c}\text { NO } \\
\text { Emissions }\end{array}$ & $\begin{array}{c}\text { Total } \\
\text { Emissions }\end{array}$ \\
\hline \hline Model 1 & 3123 & 23 & 3146 & 10 & 3051 & 12 & 3073 \\
\hline Model 2 & 3022 & 55 & 3077 & 10 & 2984 & 3006 \\
\hline Model 3 & 3068 & 69 & 3137 & 10 & 3043 & 12 & 3065 \\
\hline
\end{tabular}

Table 6. Generation resources profits of the three scenarios.

\begin{tabular}{|c|c|c|c|c|c|c|}
\hline \multirow{2}{*}{} & \multicolumn{3}{|c|}{ Generating Capacity /MW·h } & \multicolumn{3}{c|}{ Generating Profits / Ten Thousand Yuan } \\
\cline { 2 - 7 } & Thermal power & Wind Power & Hydro & Thermal Power & Wind Power & Hydro \\
\hline \hline Model 1 & 10573 & 2513 & 2408 & 202 & 128 & 153 \\
\hline Model 2 & 9982 & 2995 & 2507 & 190 & 161 & 55 \\
\hline Model 3 & 9681 & 3166 & 2647 & 185 & 58 \\
\hline
\end{tabular}

output almost meets the basic load needs, however, due to the randomness of wind power output is strong, a small unit has a fast start-stop speed is necessary for us to ensure the stability of the power supply, so at 1-4 hours, unit $3 \#$ is invoked; the output of thermal power has a great change than the other circumstances in the cooperation model, unit $2 \#$ has been called at 5-23 hours because the contract power of thermal power units are not assigned to specific units under this scenario, the contract power need to be assigned to large capacity generators priory according to the minimum coal consumption target, therefore, unit $3 \#$ uses less.

The result that the output of the wind turbine accounts for a large proportion at 1-5 hours can be received by comparing those units at the different time, what's more, start-stop speed of thermal unit need to reach a high degree, so, unit $2 \#$, if we considerate the coal consumption and start-stop speed constraints, is superior to unit 1\#, as for the 23-24 hours, the output of wind power and hydropower units can be limited because the contract capacity is no longer restricting thermal power, moreover, thermal power units can be invoked as alternate and complementary of wind turbines, furthermore, unit 1\# has not been called at 23-24 hours, and $1 \#$ and 1 \# unit have not been called at the 24 hour.

Can be seen from Fig. 1, in the contract electricity model, there are abandoned wind phenomenon at 1-5 hours and 2324 hours, and the total amount reach $1015.8 \mathrm{MW} \cdot \mathrm{h}$, the wind power output is fully consumptive available at other times. there are also existing abandoned water phenomenon at 1-3 hours and 23 hours because thermal power have the output priority to ensure thermal power contract electricity to be met under the contract power constraints, therefore, wind and hydroelectric generating output will have a significant reduction so that the excess water need to be abandoned, and the abandoned amount reaches 239.2MW - h. As for 24 hour, we can make most use of the full capacity of the hydroelectric generating output due to the thermal power contract capacity constraints are met.
As we can see from Fig. 2, wind turbine output is higher than the contract power model in an ideal energy-saving generation scheduling model, in this model abandoned wind phenomenon occurs at 1-5 hours and 23-24 hours, and abandoned air volume is $534.5 \mathrm{MW} \cdot \mathrm{h}$, which is significantly lower than the amount of the contract electricity model. At 24 hour, we cannot take full advantage of hydropower units so that abandoned water will exist due to thermal unit startstop constraints and wind turbine output constraints.

As we can see from Figure 3, abandoned wind occurs at 1-6 hours and 23-24 hours in model 3, and the abandoned wind was $322.15 \mathrm{MW} \bullet \mathrm{h}, 41 \mathrm{MW} \bullet \mathrm{h}$ respectively, total disposable air volume reaches $363.15 \mathrm{MW} \bullet \mathrm{h}$, Seen from the foregoing, this model has the smallest disposable air volume. the power load demand increased significantly at 1-6 hours combined power load demand data, due to the unit $1 \#$ has not been activated, the power load demand cannot be met by those operation units, in the one hand, thermal power increase the power output to ensure the load demand, unit 1\# meet its start needs, are met rather than being an alternate unit, which results in abandoning the wind. On the other hand, this model did not produce disposable water, that is, we can make most use of the hydropower units for the electricity grid.

\subsubsection{Benefit Comparison}

Table 5 and $\mathbf{6}$ compare the pollutant emission and generation resources profit for the three scheduling mode to analyze the economic and environmental benefits of them under three different scenarios, In order to facilitate analysis the economic and environmental benefits of various types generation resource under different scheduling modes, in this section, thermal power will be a whole so that we can use it to compare with wind power and hydropower.

Table 5 shows that coal-fired generation costs of thermal power units reduces 101 tons standard coal in an ideal en- 
ergy-saving generation scheduling model compared to contract electricity model, however, start-stop costs increased 32 tons standard coal. The reasons for this phenomenon conclude the following. in this model, Wind power and hydroelectric generating have the priority of power output so that grid-connected electricity increases, which leads to increase the replacement amount of the thermal power generation capacity, consequently, the total cost of coal-fired electricity generation reduce, moreover, unit $3 \#$ has been used for backup services to do the backup of wind turbine output, which increases the overall cost of start-stop. Similarly, in the cooperation mode, coal-fired power generation costs will decrease due to the growing output of wind and hydro units compared to contract electricity model, however, coal-fired power generation costs are higher than it in the ideal energysaving scheduling model, that's because unit $2 \#$ power output increases in this model, unit coal consumption is higher than unit 1\#'s, therefore, the total cost of coal-fired power generation increase, the start-stop cost of thermal power units also increased significantly due to the grid-connected recruitment of wind power. Overall, for the environmental benefits, ideal energy-saving scheduling model is superior to cooperation model, and cooperation model is superior to contract electricity models.

Compared generation resources profit of these three models in Table 6, cooperation model owns the highest wind power, thermal power and hydropower generating capacity, and has the highest overall generating profits, that is, it has the best economic benefits. Every coin has two sides; its thermal power should lower its profits significantly, wind and hydro power ought to increase its profits significantly.

In summary, Compared to the other two scheduling model, in the cooperation model, multiple types generation resources can prevent the thermal power resources from participating in power generation, and increase the generating capacity of wind power and hydropower resources so that reduce emissions significantly. We, if using the resource scheduling optimization model based on cooperation, can take advantage of the environmental benefits of wind power, hydropower and other renewable energy sources when making optimal use of power resources.

\section{CONCLUSION}

This paper aims at the contract power, the ideal energy generation scheduling and generating resource scheduling optimization model under the mutual cooperation scenarios to establish model for the comparison and analysis of all types of power generation resource scheduling model with different objectives and constraints. The following is the conclusion which is obtained by example simulation and comparative analysis.

(1) Unit output distribution of contract power model has certain plans and stability, thermal power units have smallest start-stop time. But, it will lead to the highest cost of coal consumption and pollutant emissions, what's more, it has the smallest utilization of renewable generation resources;
(2) The ideal energy generation scheduling has the smallest cost of coal consumption and pollutant emissions, however, the use of renewable generation resources will be limited due to its stability constraints, while bringing greater start-stop costs and equipment loss costs;

(3) Coal consumption and pollution emissions of the cooperative model have a significant reduce, renewable generation resources are fully utilized, and meanwhile, it achieves the highest overall profit value.

According to study results, the thermal power resources generating profits will be reduced under the cooperative model, which will affect the enthusiasm of thermal power generation resources to participate in resource scheduling. In order to overcome this difficulty, it is necessary for us to study the rational allocation of the profits of multi-type power generation resource scheduling.

\section{CONFLICT OF INTEREST}

The authors confirm that this article content has no conflict of interest.

\section{ACKNOWLEDGEMENTS}

Declared none.

\section{REFERENCES}

[1] Shang Jin-cheng, Zhang Li-qing, "Research and Application of Technologies in Energy-Saving, Emission-Reducing and Optimal Resource Allocation of Electric Power System", Power System Technology, vol. 31, no. 22, pp. 59-63, 2007.

[2] Bao Bing, "A Reserch on the Policy Implementation Performance of China's Energy Saving and Emission Reduction in Power ", Harbin Institute of Technology, 2010.

[3] Wu Jie-kang, Li Ying, "The Multi-objective Optimized Scheduling of Hydro-thermal Power System", Modern Electricity Power, vol. 28, pp. 52-57, 2011.

[4] LIU Xiao, AI Xin, PENG Qian, "Optimal Dispatch Coordinating Power Generation with Carbon Emission Permit for Wind Farms Integrated Power Grid Considering Demand Response", Power System Technology, vol. 36, pp. 213-128, 2012.

[5] Wu Hong-yu, Guan Xiao-hong, Zhai Qiao-zhu, Gao Feng, "Shortterm Hydrothermal Scheduling Using Mixed-integer Linear Programming", Proceedings of the CSEE, vol. 29, pp. 82-88, 2009

[6] Chen Guo-xuan, Xu Yin-shan, "Research on the Operation of Cascade Power Stations Based on Contract Power Quantity", China Rural Water and Hydropower, vol. 5, pp. 159-164, 2011.

[7] Zhang Li, Liu Jun-yong, Liu Ji-chun, Liu Jia-jia, Wu Zhi-yun, Wen Li-li, "Study on scheduling and resolution algorithm of annual contract volume for thermal power units", RELAY, vol. 35, pp. 64-69, 2007.

[8] Tang Yong-jun, Liu Dong, Ruan Qian-tou, "Optimal Allocation of Distributed Generation and Its Parallel Computation Considering Energy-saving Dispatching", Automation of Electric Power Systems, vol. 32, pp. 92-97, 2008.

[9] Su Peng, Liu Tian-qi , Zhao Guo-bo , Zhang Jiong, "An Improved Particle Swarm Optimization Based Multi-Objective Load Dispatch Under Energy Conservation Dispatching", Power System Technology, vol. 33, pp. 48-53, 2009.

[10] Shang Jin-cheng, "Research on Economic Compensation Mechanism for Energy-saving Generation Dispatch Part One Design and Analysis of Economic Compensation Mechanism Based on Administrative Means", Automation of Electric Power Systems , vol. 33, pp. 44-48, 2009. 
[11] Shang Jin-cheng, "Research on Economic Compensation Mechanism for Energy-saving Generation Dispatch Part Two Design and Analysis of Economic Compensation Mechanism Based on Market Mechanism", Automation of Electric Power Systems, vol. 33, pp. 46-50, 2009 .
[12] Shang Jin-cheng, Pang Bo, Wang Qing-min, He Yang, "Market Model and Algorithms for Economic Compensation Mechanism of Energy-Saving Generation Dispatch", Power System Technology, vol. 34 , pp. 62-68, 2010

Received: September 16, 2014

Revised: December 23, 2014

Accepted: December 31, 2014

(C) Hong-Liang et al.; Licensee Bentham Open.

This is an open access article licensed under the terms of the (https://creativecommons.org/licenses/by/4.0/legalcode), which permits unrestricted, noncommercial use, distribution and reproduction in any medium, provided the work is properly cited. 